\title{
Article
}

\section{Cangrelor Use in Routine Practice: A Two-Center Experience}

\author{
Niels M. R. van der Sangen ${ }^{1}{ }^{1}$, Ho Yee Cheung ${ }^{1}$, Niels J. W. Verouden ${ }^{2}$, Yolande Appelman ${ }^{2}$, \\ Marcel A. M. Beijk ${ }^{1}$, Bimmer E. P. M. Claessen ${ }^{1}$, Ronak Delewi ${ }^{1}$, Paul Knaapen ${ }^{2}$, Jorrit S. Lemkes ${ }^{2}$, \\ Alexander Nap ${ }^{2}$, M. Marije Vis ${ }^{1}$, Wouter J. Kikkert ${ }^{1,3}$ and José P. S. Henriques ${ }^{1, *(1)}$ \\ 1 Department of Cardiology, Amsterdam UMC, University of Amsterdam, Amsterdam Cardiovascular \\ Sciences, 1105 AZ Amsterdam, The Netherlands; n.m.r.vandersangen@amsterdamumc.nl (N.M.R.v.d.S.); \\ h.y.cheung@amsterdamumc.nl (H.Y.C.); m.a.beijk@amsterdamumc.nl (M.A.M.B.); \\ b.e.claessen@amsterdamumc.nl (B.E.P.M.C.); r.delewi@amsterdamumc.nl (R.D.); \\ m.m.vis@amsterdamumc.nl (M.M.V.); w.j.kikkert@olvg.nl (W.J.K.) \\ 2 Department of Cardiology, Amsterdam UMC, VU University, Amsterdam Cardiovascular Sciences, \\ 1081 HV Amsterdam, The Netherlands; c.verouden@amsterdamumc.nl (N.J.W.V.); \\ y.appelman@amsterdamumc.nl (Y.A.); p.knaapen@amsterdamumc.nl (P.K.); \\ j.lemkes@amsterdamumc.nl (J.S.L.); a.nap@amsterdamumc.nl (A.N.) \\ 3 Department of Cardiology, Onze Lieve Vrouwe Gasthuis, 1091 AC Amsterdam, The Netherlands \\ * Correspondence: j.p.henriques@amsterdamumc.nl
}

check for updates

Citation: van der Sangen, N.M.R.; Cheung, H.Y.; Verouden, N.J.W.; Appelman, Y.; Beijk, M.A.M.;

Claessen, B.E.P.M.; Delewi, R.; Knaapen, P.; Lemkes, J.S.; Nap, A.; et al. Cangrelor Use in Routine Practice: A Two-Center Experience. J. Clin. Med. 2021, 10, 2829. https:// doi.org/10.3390/jcm10132829

Academic Editor: Nicola Cosentino

Received: 1 June 2021

Accepted: 24 June 2021

Published: 26 June 2021

Publisher's Note: MDPI stays neutral with regard to jurisdictional claims in published maps and institutional affiliations.

Copyright: (c) 2021 by the authors. Licensee MDPI, Basel, Switzerland. This article is an open access article distributed under the terms and conditions of the Creative Commons Attribution (CC BY) license (https:// creativecommons.org/licenses/by/ $4.0 /)$.

\begin{abstract}
Cangrelor is the first and only intravenous $\mathrm{P}_{2} \mathrm{Y}_{12}$-inhibitor and is indicated when (timely) administration of an oral $\mathrm{P}_{2} \mathrm{Y}_{12}$ inhibitor is not feasible in patients undergoing percutaneous coronary intervention (PCI). Our study evaluated the first years of cangrelor use in two Dutch tertiary care centers. Cangrelor-treated patients were identified using a data-mining algorithm. The cumulative incidences of all-cause death, myocardial infarction, definite stent thrombosis and major bleeding at $48 \mathrm{~h}$ and 30 days were assessed using Kaplan-Meier estimates. Predictors of 30-day mortality were identified using uni- and multivariable Cox regression models. Between March 2015 and April 2021, 146 patients (median age 63.7 years, $75.3 \%$ men) were treated with cangrelor. Cangrelor was primarily used in ST-segment elevation myocardial infarction (STEMI) patients (84.2\%). Approximately half required cardiopulmonary resuscitation $(54.8 \%)$ or mechanical ventilation $(48.6 \%)$. The cumulative incidence of all-cause death was $11.0 \%$ and $25.3 \%$ at $48 \mathrm{~h}$ and 30 days, respectively. Two cases $(1.7 \%)$ of definite stent thrombosis, both resulting in myocardial infarction, occurred within 30 days, but after $48 \mathrm{~h}$. No other cases of recurrent myocardial infarction transpired within 30 days. Major bleeding occurred in $5.6 \%$ and $12.5 \%$ of patients within $48 \mathrm{~h}$ and 30 days, respectively. Cardiac arrest at presentation was an independent predictor of 30-day mortality (adjusted hazard ratio 5.20, 95\%-CI: 2.10-12.9, $p<0.01$ ). Conclusively, cangrelor was used almost exclusively in STEMI patients undergoing PCI. Even though cangrelor was used in high-risk patients, its use was associated with a low rate of stent thrombosis.
\end{abstract}

Keywords: cangrelor; antiplatelet therapy; percutaneous coronary intervention

\section{Introduction}

In 2015 cangrelor became the first intravenous $\mathrm{P}_{2} \mathrm{Y}_{12}$-inhibitor approved for clinical use by the European Medicines Agency (EMA). Cangrelor can be used during percutaneous coronary intervention (PCI), alongside aspirin, in patients who have not received an oral $\mathrm{P}_{2} \mathrm{Y}_{12}$-inhibitor prior to PCI and when oral P2 $\mathrm{Y}_{12}$-inhibition is not feasible [1,2]. As opposed to oral $\mathrm{P} 2 \mathrm{Y}_{12}$-inhibtors, cangrelor has the pharmacokinetic advantage of reducing platelet reactivity within minutes of administration and returning normal platelet function within 30-60 min after treatment discontinuation due to a relatively short half-life [3].

The efficacy and safety of cangrelor was first evaluated in the three Cangrelor versus Standard Therapy to Achieve Optimal Management of Platelet Inhibition (CHAMPION) randomized clinical trials [4-6]. Pooled data of these trials $(n=24,910)$ showed that the use 
of cangrelor was associated with a reduction in peri-procedural ischemic complications (i.e., all-cause death, myocardial infarction, ischemia-driven revascularization or stent thrombosis within $48 \mathrm{~h}$ ) and an increase in minor (but not major) bleeding events as compared to clopidogrel [7]. Ever since cangrelor gained market authorization, there has been limited data on its use and outcomes in cangrelor-treated patients in routine practice. Therefore, the objective of this study was to describe (i) patient and procedural characteristics, (ii) clinical outcomes and (iii) the transition to oral $\mathrm{P}_{2} \mathrm{Y}_{12}$-inhibitors of cangrelor-treated patients undergoing coronary angiography or PCI in two Dutch tertiary PCI centers during the first years of routine cangrelor use.

\section{Materials and Methods}

\subsection{Source Population and Standard Procedures}

The data analyzed in this manuscript were obtained from cangrelor-treated patients undergoing coronary angiography with intent of PCI in the two affiliated hospitals of the Amsterdam UMC, University Medical Centers. Both hospitals are high-volume, tertiary PCI centers situated in Amsterdam, the Netherlands. Patients with ST-segment elevation myocardial infarction (STEMI) were routinely pretreated with $160 \mathrm{mg}$ aspirin (or $500 \mathrm{mg}$ aspirin i.v. in unconscious or noxious patients), $180 \mathrm{mg}$ ticagrelor or $60 \mathrm{mg}$ prasugrel and $5000 \mathrm{IU}$ of unfractionated heparin as soon as the diagnosis was established. In patients with non-ST-segment elevation myocardial infarction (NSTEMI) and unstable angina a similar loading dose of aspirin and ticagrelor or prasugrel was combined with $2.5 \mathrm{mg}$ fondaparinux s.c. once daily until PCI. In patients using oral anticoagulants ticagrelor or prasugrel was substituted for clopidogrel. Patients undergoing PCI for chronic coronary syndrome were started on $75 \mathrm{mg}$ clopidogrel and $100 \mathrm{mg}$ aspirin at least 3 days prior to the procedure. All patients received a weight-adjusted dose of unfractionated heparin at the catheterization laboratory and an additional dose after $60 \mathrm{~min}$ if the activated clotting time fell below $250 \mathrm{~s}$. In both centers, cangrelor was indicated if pretreatment with an oral P2Y $\mathrm{Y}_{12}$-inhbitor was not feasible or desirable and PCI could not be postponed. Cangrelor was administered as a bolus of $30 \mu \mathrm{g} / \mathrm{kg}$ followed by an infusion of $4 \mu \mathrm{g} / \mathrm{kg} / \mathrm{min}$ for at least $2 \mathrm{~h}$ or the duration of the procedure, whichever lasted longer. Patients received a loading dose of an oral $\mathrm{P}_{2} \mathrm{Y}_{12}$-inhibitor directly after completion of cangrelor infusion.

\subsection{Patient Identification Method and Data Collection}

A Boolean retrieval query was developed in order to identify cangrelor-treated patients based on data from their electronic health record. This query was developed using a graphic user interface data-mining algorithm with text-mining features (CTcue, version 2.1.13, Amsterdam, The Netherlands). Both structured and unstructured data from electronic health records, such as drug prescriptions and procedural reports, were integrally searched using the data-mining algorithm with the following search terms: 'Cangrelor' and 'Kengrexal'. Additional filters were applied to exclude patients under the age of 18 and patients treated with cangrelor before 23 March 2015, the date of the EMA marketing authorization. The results from the automated search were manually verified. Patients were given a four-week period to object to the (re)use of their clinical care data. Demographic, clinical and procedural characteristics were collected through chart review.

\subsection{Clinical Outcomes}

The primary endpoints were all-cause death, myocardial infraction, definite stent thrombosis and major bleeding at $48 \mathrm{~h}$ and 30 days. Myocardial infarction was defined in accordance with the fourth universal definition of myocardial infarction [8]. Definite stent thrombosis was defined according to the Academic Research Consortium (ARC) definition [9]. Bleeding events were classified according to the Bleeding Academic Research Consortium (BARC) bleeding definition [10]. BARC type 3 to 5 bleeding was considered major, while BARC type 2 bleeding was considered minor. All primary endpoints were adjudicated by two authors (N.M.R.v.d.S. and H.Y.C.). Timing of oral loading dose was 
subdivided in pre-, during or post-PCI. Furthermore, the choice for a specific $\mathrm{P}^{2} \mathrm{Y}_{12^{-}}$ inhibitor was recorded (clopidogrel, ticagrelor or prasugrel). In case of an oral $\mathrm{P}_{2} \mathrm{Y}_{12^{-}}$ inhibitor switch, only the first choice was reported. The possible administration of an additional, second loading dose ('reloading') was also noted.

\subsection{Statistical Methods}

The primary objective of our study was descriptive in nature; therefore, no formal sample size calculation was performed. Continuous variables were reported as mean (standard deviation) or median (interquartile range) and categorical variables were reported as number of patients (percentage). Cumulative incidences of the primary endpoints were assessed using Kaplan-Meier estimates at $48 \mathrm{~h}$ and 30 days. Data from patients who did not have a primary endpoint event between hospital admission and 30 days were censored at the time of death, the time of last follow-up or 30 days, whichever came first. Cox proportional hazard models were used to identify (potential) predictors of 30-day mortality. Uni- and multivariable models were used. In the latter, age, sex and all statistically significant predictors from the univariate analyses were included. A $p$-value of $<0.05$ was considered statistically significant. Statistical analyses were performed using SPSS version 26 (SPSS Inc., Chicago, IL, USA) and R studio version 3.6.1 (Vienna, Austria).

\section{Results}

\subsection{Patient and Procedural Characteristics}

From March 2015 through April 2021, 166 patients were identified by our data-mining algorithm. A total of 150 patients were considered to be cangrelor-treated after manual validation of the search results. In 16 patients, cangrelor treatment was considered but ultimately not administered. Four patients objected to the (re)use of their clinical care data. Hence, 146 patients were included in the data analysis (Figure 1).

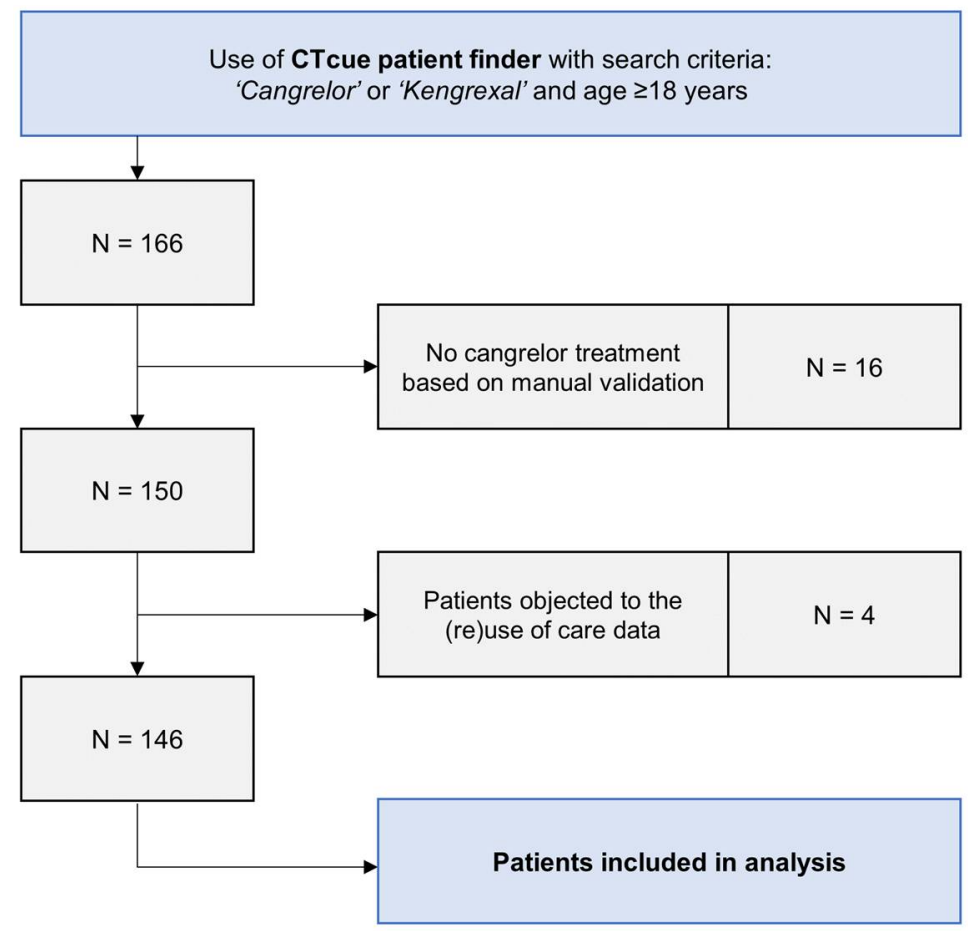

Figure 1. Flowchart of cangrelor-treated patients in both participating centers.

Baseline and procedural characteristics of cangrelor-treated patients are presented in Tables 1 and 2. Cangrelor-treated patients had a mean age of 63.7 years and were most often male $(75.3 \%)$. Cangrelor was primarily used in STEMI patients $(84.2 \%)$ with high-risk features, such as cardiac arrest $(54.8 \%)$, mechanical ventilation $(48.6 \%)$ and/or 
cardiogenic shock (45.2\%). Eighteen patients (12.3\%) received mechanical circulatory support during admission. Radial access was used slightly more than femoral access (54.8\% vs. $45.2 \%)$. PCI was performed in 140 patients $(94.3 \%)$ using drug-eluting stents in all but eight cases. Twenty-six patients underwent multi-vessel PCI (18.6\%) and thrombectomy was performed in 28 patients $(20.0 \%)$. All patients started cangrelor right before or during coronary angiography. The vast majority of patients underwent coronary angiography within the first $24 \mathrm{~h}$ of hospital admission (93.8\%).

Almost all patients received unfractionated heparin during coronary angiography (97.9\%). One patient $(0.7 \%)$ received glycoprotein $\mathrm{IIb} / \mathrm{III}$ a bailout therapy using abciximab alongside cangrelor. Pretreatment with an oral $\mathrm{P}_{2} \mathrm{Y}_{12}$-inhibitor was initiated before PCI in approximately one quarter of cases (26.6\%), while $2.9 \%$ and $70.5 \%$ of cases received their initial loading dose during or after PCI. Five patients $(3.6 \%)$ received an additional $\mathrm{P}_{2} \mathrm{Y}_{12}$-inhibitor loading dose ('reloading') due to vomiting or nausea after being pretreated before the procedure. Ticagrelor was the most commonly used $\mathrm{P}_{2} \mathrm{Y}_{12}$-inhibitor (89.2\%), although some patients were treated with clopidogrel (10.8\%).

Table 1. Baseline characteristics and clinical presentation of cangrelor-treated patients.

\begin{tabular}{|c|c|}
\hline & $\begin{array}{l}\text { Cangrelor-Treated Patients } \\
\qquad(n=146)\end{array}$ \\
\hline \multicolumn{2}{|l|}{ Demographic Characteristics } \\
\hline Age (years) & $63.7 \pm 11.7$ \\
\hline Male, no./total no. $(\%)$ & $110 / 146(75.3 \%)$ \\
\hline Body mass index $\left(\mathrm{kg} / \mathrm{m}^{2}\right) *$ & $26.8 \pm 3.7$ \\
\hline Hypertension, no./total no. (\%) & $50 / 140(35.7 \%)$ \\
\hline Dyslipidemia, no./total no. (\%) & $35 / 104(33.7 \%)$ \\
\hline Current smokers, no./total no. (\%) & $46 / 118(39.0 \%)$ \\
\hline Diabetes mellitus, no./total no. $(\%)$ & $23 / 141(16.3 \%)$ \\
\hline Insulin-dependent diabetes, no./total no. (\%) & $7 / 141(5.0 \%)$ \\
\hline Positive family history, no./total no. $(\%)+$ & $35 / 87(40.2 \%)$ \\
\hline Chronic kidney disease, no/total no. (\%) $\ddagger$ & $6 / 143(4.2 \%)$ \\
\hline Prior myocardial infarction, no./total no. (\%) & $18 / 143(12.6 \%)$ \\
\hline Prior PCI, no./total no. (\%) & $19 / 143(13.3 \%)$ \\
\hline Prior CABG, no./total no. $(\%)$ & $6 / 143(4.2 \%)$ \\
\hline Prior stroke or TIA, no./total no. (\%) & $9 / 143(6.3 \%)$ \\
\hline \multicolumn{2}{|l|}{ Clinical presentation } \\
\hline \multicolumn{2}{|l|}{ Diagnosis at presentation, no./total no. (\%) } \\
\hline STEMI $(\%)$ & $123 / 146(84.2 \%)$ \\
\hline NSTEMI & $10 / 146(6.8 \%)$ \\
\hline Unstable angina & $2 / 146(1.4 \%)$ \\
\hline Chronic coronary syndrome) & $4 / 146(2.7 \%)$ \\
\hline Other diagnosis $(\%)$ & $7 / 146(4.8 \%)$ \\
\hline \multicolumn{2}{|l|}{ Killip classification, no./total no. (\%) } \\
\hline Class I $(\%)$ & $62 / 146(42.5 \%)$ \\
\hline Class II & $14 / 146(9.6 \%)$ \\
\hline Class III & $4 / 146(2.7 \%)$ \\
\hline Class IV & $66 / 146(45.2 \%)$ \\
\hline Cardiac arrest at presentation, no./total no. (\%) & $80 / 146(54.8 \%)$ \\
\hline Mechanical ventilation, no./total no. (\%) & $71 / 146(48.6 \%)$ \\
\hline Mechanical circulatory support, no./total no. (\%) § & $18 / 146(12.3 \%)$ \\
\hline
\end{tabular}

Plus-minus values are mean \pm standard deviation or number of patients (percentage). CABG denotes coronary artery bypass grafting, NSTEMI non-ST-segment elevation myocardial infarction, PCI percutaneous coronary intervention, STEMI ST-segment elevation myocardial infarction, TIA transient ischemic attack. * Body mass index was calculated by dividing weight in kilograms by the square of the height in meters and was available in 116/146 patients. + Positive family history was defined as a (fatal) cardiovascular event and/or an established diagnosis of cardiovascular disease in a first-degree relatives before 65 years of age. $\ddagger$ Chronic kidney disease was defined as an estimated glomerular filtration rate $<60 \mathrm{~mL} / \mathrm{min} / 1.73 \mathrm{~m}^{2}$. § Mechanical circulatory support was defined as the use of extracorporeal membrane oxygenation (ECMO), Impella or an intra-aortic balloon pump (IABP). 
Table 2. Procedural characteristics of cangrelor-treated patients.

\begin{tabular}{|c|c|}
\hline & $\begin{array}{l}\text { Cangrelor-Treated Patients } \\
\qquad(n=146)\end{array}$ \\
\hline \multicolumn{2}{|l|}{ Procedural Characteristics } \\
\hline Procedural length (min) & $44(34-62)$ \\
\hline \multicolumn{2}{|l|}{ Access route, no./total no. (\%) } \\
\hline Radial access & $80 / 146(54.8 \%)$ \\
\hline Femoral access & $66 / 146(45.2 \%)$ \\
\hline PCI, no./total no. (\%) & $140 / 146(95.9 \%)$ \\
\hline Drug-eluting stent & $132 / 140(94.3 \%)$ \\
\hline Balloon angioplasty & $8 / 140(5.7 \%)$ \\
\hline \multicolumn{2}{|l|}{ Target vessel, no./total no. $(\%) *$} \\
\hline Left main & $18 / 140(12.9 \%)$ \\
\hline Left anterior descending & $76 / 140(54.3 \%)$ \\
\hline Left circumflex artery & $25 / 140(17.9 \%)$ \\
\hline Ramus intermedius & $10 / 140(7.1 \%)$ \\
\hline Right coronary artery & $45 / 140(32.1 \%)$ \\
\hline Saphenous vein graft & $1 / 140(0.7 \%)$ \\
\hline Multi-vessel PCI, no./total no. (\%) & $26 / 140(18.6 \%)$ \\
\hline Aspiration thrombectomy, no./total no. (\%) & $28 / 140(20.0 \%)$ \\
\hline Unsuccessful or no PCI, no./total no. (\%) & $6 / 146(4.1 \%)$ \\
\hline \multicolumn{2}{|l|}{ Procedural medication } \\
\hline Aspirin loading dose, no./total no. (\%) & $138 / 146(94.5 \%)$ \\
\hline $\mathrm{P}_{2} \mathrm{Y}_{12}$-inhibitor loading dose, no./total no. (\%) & $139 / 146(95.2 \%)$ \\
\hline \multicolumn{2}{|l|}{ Type of oral $\mathrm{P}_{2} \mathrm{Y}_{12}$-inhibitor, no./total no. (\%) } \\
\hline Clopidogrel & $15 / 139(10.8 \%)$ \\
\hline Prasugrel & $0 / 139(0.0 \%)$ \\
\hline Ticagrelor & $124 / 139(89.2 \%)$ \\
\hline \multicolumn{2}{|c|}{ Timing of $\mathrm{P}_{2} \mathrm{Y}_{12}$-inhibitor loading dose, no./total no. (\%) } \\
\hline Pre-PCI & $37 / 139(26.6 \%)$ \\
\hline During PCI & $4 / 139(2.9 \%)$ \\
\hline Post-PCI & $98 / 139(70.5 \%)$ \\
\hline $\mathrm{P}_{2} \mathrm{Y}_{12}$-inhibitor reloading, no./total no. $(\%) \dagger$ & $5 / 139(3.6 \%)$ \\
\hline \multicolumn{2}{|l|}{ Oral anticoagulants use, no./total no. (\%) } \\
\hline Vitamin K antagonist & $5 / 146(3.4 \%)$ \\
\hline Direct oral anticoagulant & $6 / 146(4.1 \%)$ \\
\hline \multicolumn{2}{|l|}{ Peri-procedural anticoagulants, no./total no. (\%) } \\
\hline Unfractionated heparin & $143 / 146(97.9 \%)$ \\
\hline Glycoprotein IIb/IIIa inhibitors & $1 / 146(0.7 \%)$ \\
\hline
\end{tabular}

Plus-minus values are median (25th-75th interquartile range) or number of patients (percentage). PCI denotes percutaneous coronary intervention. ${ }^{*}$ Right coronary artery includes right posterolateral branch, left anterior descending includes diagonal branches, left circumflex artery includes marginal branches. $+\mathrm{P}_{2} \mathrm{Y}_{12}$-inhibitor reloading was defined as receiving an additional (i.e., second) loading dose after the initial loading dose during the same hospital admission.

\subsection{Clinical Outcomes}

Clinical outcomes at $48 \mathrm{~h}$ and 30 days follow-up are presented in Table 3 and Figure 2. The incidence of all-cause death was $11.0 \%$ and $25.3 \%$ at $48 \mathrm{~h}$ and 30 days, respectively. All deaths within $48 \mathrm{~h}$ had a cardiovascular cause. One patient died due to intracranial bleeding 19 days after cangrelor treatment. The median time until death was 3 days (IQR 1-9). Definite stent thrombosis, resulting in myocardial infarction (type $4 b$ ), occurred in two separate cases $(1.7 \%)$. The first case of stent thrombosis (complete stent occlusion) occurred in a 51-year-old male 10 days after presentation with cardiac arrest and anterior STEMI. The patient was initially treated with a drug-eluting stent in the proximal left anterior descending (LAD) coronary artery and was transitioned to ticagrelor in conjunction with aspirin. Upon re-angiography at day 10 indicated by refractory angina and ischemic electrocardiogram changes, optical coherence tomography (OCT) revealed stent malapposition and a non-obstructing edge dissection proximal of the stent. Balloon dilatation 
and thrombosuction were ultimately successfully. The second case of stent thrombosis occurred at day 21 of admission (and 8 days after cangrelor therapy) in a 71-year-old male admitted for ischemic heart failure and (in-hospital) cardiac arrest. His medical history included active colorectal carcinoma without signs of metastases for which a hemicolectomy was planned. The patient was initially on clopidogrel and aspirin, but was switched to ticagrelor and aspirin. Re-angiography indicated by ventricular fibrillation showed stent thrombosis (complete stent occlusion) of the stent implanted days before in the mid LAD. Multiple attempts of wire passage were unsuccessful and the patient expired four days later. No other cases of myocardial infarction transpired within 30 days. Major or minor bleeding occurred in $13.8 \%$ and $22.0 \%$ of patients within $48 \mathrm{~h}$ and 30 days, respectively. The estimated cumulative incidence of major bleeding was $5.6 \%$ and $12.5 \%$ at $48 \mathrm{~h}$ and 30 days. Out of the eight major bleeding events within $48 \mathrm{~h}$, two were access site-related, two were device-related, one was gastrointestinal, one was intracranial, one was intrathoracic and one was presumed to be based on a significant drop in hemoglobin, but with an unidentified source. In total, four gastrointestinal, four device-related, three access site-related, two intracranial, one intrathoracic and three presumed major bleeding events occurred within 30 days of hospital admission.

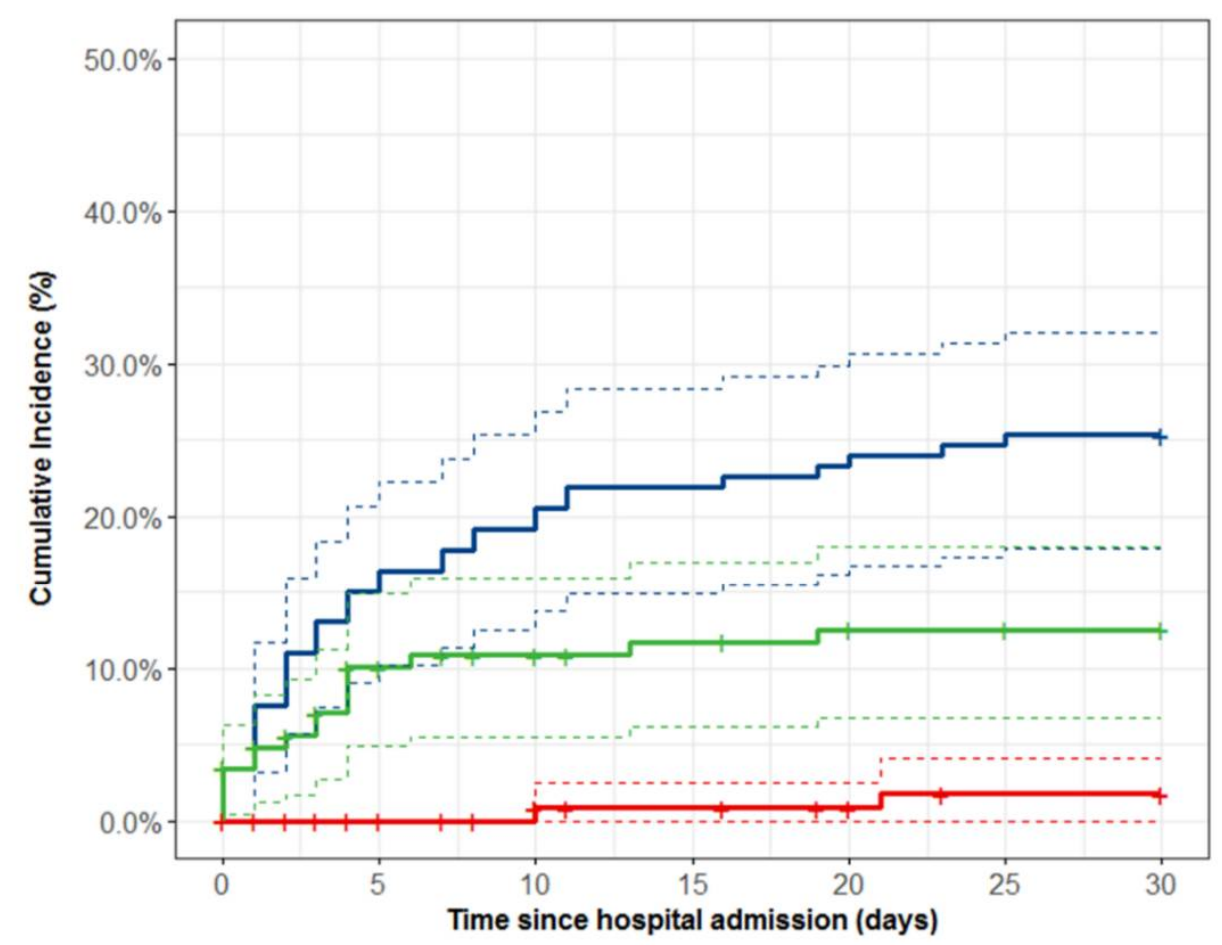

No. at risk

\begin{tabular}{|c|c|c|c|c|c|c|c|}
\hline $\begin{array}{l}\text { All-cause mortality } \\
\text { Ischemic events } \\
\text { Major bleeding events }\end{array}$ & $\begin{array}{l}146 \\
146 \\
146\end{array}$ & $\begin{array}{l}124 \\
124 \\
116\end{array}$ & $\begin{array}{l}118 \\
118 \\
109\end{array}$ & $\begin{array}{l}114 \\
113 \\
106\end{array}$ & $\begin{array}{l}112 \\
111 \\
104\end{array}$ & $\begin{array}{l}110 \\
108 \\
103\end{array}$ & $\begin{array}{l}109 \\
108 \\
102\end{array}$ \\
\hline
\end{tabular}

Figure 2. Kaplan-Meier curve including 95\% confidence interval (dashed lines) for mortality, ischemic and bleeding events in cangrelor-treated patients. Ischemic events were defined as stent thrombosis or (recurrent) myocardial infarction. Major bleeding events were defined as BARC type 3 to 5 bleeding. 
Table 3. Cumulative incidence of ischemic and bleeding events at $48 \mathrm{~h}$ and 30 days.

\begin{tabular}{lcc}
\hline & \multicolumn{2}{c}{$\begin{array}{c}\text { Cangrelor-Treated Patients } \\
(\boldsymbol{n}=\mathbf{1 4 6})\end{array}$} \\
\hline All-cause mortality, no. of patients (\%) & $\mathbf{4 8 ~ h}$ & $\mathbf{3 0 ~ D a y s ~}$ \\
Myocardial infarction, no. of patients (\%) & $16(11.0 \%)$ & $37(25.3 \%)$ \\
Definite stent thrombosis, no. of patients $(\%)$ & $0(0.0 \%)$ & $2(1.7 \%)$ \\
Major bleeding, no. of patients (\%) & $0(0.0 \%)$ & $2(1.7 \%)$ \\
$\quad$ Access site bleeding & $8(5.6 \%)$ & $17(12.5 \%)$ \\
Major or minor bleeding, no. of patients (\%) & $2(25.0 \%)^{*}$ & $3(17.6 \%)^{*}$ \\
$\quad$ Access site bleeding & $20(13.8 \%)$ & $31(22.0 \%)$ \\
\hline
\end{tabular}

Percentages are Kaplan-Meier estimates of the cumulative incidence of the clinical endpoints. * Percentage of bleeding events defined as access site bleeding relative to all bleeding events.

Results of the Cox proportional hazard analyses of predictors for 30-day mortality are shown in Table 4. Cardiac arrest at presentation was a statistically significant predictor for 30-day mortality (unadjusted hazard ratio 5.00, 95\%-CI: 2.08-12.0, $p<0.01$ ). After adjustment for age and sex in the multivariable model, cardiac arrest remained an independent predictor of 30-day mortality (adjusted hazard ratio 5.20, 95\%-CI: 2.10-12.9, $p<0.01$ ).

Table 4. Predictors of 30-day mortality in cangrelor-treated patients.

\begin{tabular}{lcccc}
\hline & \multicolumn{2}{c}{ Univariate Analysis } & \multicolumn{2}{c}{ Multivariable Analysis } \\
& HR (95\%-CI) & $p$-Value & HR (95\%-CI) & $p$-Value \\
\hline Age per year * & $1.00(0.97-1.02)$ & 0.74 & $1.01(0.98-1.04)$ & 0.71 \\
Male sex & $1.41(0.62-3.21)$ & 0.41 & $0.92(0.40-2.14)$ & 0.85 \\
Hypertension & $1.56(0.80-3.04)$ & 0.19 & & \\
Diabetes mellitus & $0.80(0.31-2.05)$ & 0.64 & \\
Current smoker & $0.82(0.37-1.84)$ & 0.63 & \\
Pervious MI & $0.61(0.19-2.00)$ & 0.61 & & \\
Previous revascularization + & $0.93(0.39-2.24)$ & 0.87 & & $<0.01$ \\
STEMI at presentation & $1.63(0.58-4.59)$ & 0.36 & & \\
Cardiac arrest at presentation & $5.00(2.08-12.0)$ & $<0.01$ & $5.20(2.10-12.9)$ & $<$
\end{tabular}

CI denotes confidence interval, HR hazard ratio, MI myocardial infarction, PCI percutaneous coronary intervention, STEMI ST-segment elevation myocardial infarction. * Note that the HR corresponds to a unit increase in the explanatory variable. + Revascularization was defined as previous PCI and/or CABG.

\section{Discussion}

The most important findings of the current study are as follows: (i) intravenous $\mathrm{P}_{2} \mathrm{Y}_{12}$ inhibition with cangrelor is used in a small proportion of patients undergoing invasive cardiac procedures, (ii) patients receiving cangrelor are generally high-risk patients (including patients after cardiac arrest, on mechanical ventilation and/or in cardiogenic shock), and (iii) patients receiving cangrelor had low rates of stent thrombosis and acceptable bleeding rates, given their high-risk profile.

In our study cangrelor was primarily used in high-risk STEMI patients. These findings are consistent with previous work in other registries [11,12]. Grimfjärd et al. already showed that cangrelor was used almost exclusively in STEMI patients (98.2\% of all cases), often presenting with cardiac arrest (17.8\%), in the Swedish Coronary Angiography and Angioplasty Registry (SCAAR) between 2016 and 2018 [11]. Conversely, in the original CHAMPION trials, only $11.6 \%$ of the pooled study population consisted of STEMI patients [7]. Notably, patients with cardiogenic shock or cardiac arrest were not included in the CHAMPION trials, so the efficacy and safety of cangrelor in these patients is relatively unknown.

\subsection{Ischemic and Bleeding Complications}

It has been well established that high-risk patients, mainly cardiac arrest or cardiogenic shock patients, have an excess risk of early ischemic complications, such as stent 
thrombosis [13]. High on-treatment platelet reactivity has been reported up to several hours after an oral $\mathrm{P}_{2} \mathrm{Y}_{12}$-inhibitor loading dose (even with ticagrelor or prasugrel) and there is a high degree of inter-individual variability [14,15]. The delayed onset of action has been attributed to factors such as reduced drug bioavailability due to impaired drug absorption (e.g., in cardiogenic shock patients) [16,17]. Organ hypoperfusion also effects the hepatic cytochrome P450 enzyme system, which is responsible for the biotransformation of clopidogrel and prasugrel (both prodrugs) to their active metabolites [18]. Likewise, iatrogenic factors such as medically induced hypothermia (after cardiac arrest) and morphine use can result in an attenuated antiplatelet effect [19-22]. Cangrelor circumvents some of the contribution factors to the excess ischemic risk. In the present study, no cases of stent thrombosis occurred in the first $48 \mathrm{~h}$ after PCI, suggesting that platelet inhibition during this period was adequate. Similarly, in a retrospective evaluation of cangrelor use and peri-procedural outcomes in patients in clinical shock, Vaduganathan et al. reported that only one out of $147(0.7 \%)$ cangrelor-treated patients had a stent thrombosis within $48 \mathrm{~h}$ [12]. Additionally, in the SCAAR registry only $0.7 \%$ of all cangrelor-treated STEMI patients had a stent thrombosis within 30 days [11]. Although the reported rate of stent thrombosis in these patients has been reassuring, the balance between ischemic protection and additional bleeding risk remains precarious. Critically ill patients are at increased risk of (major) bleeding, partially due to frequent use of femoral access, mechanical circulatory support devices and gastro-intestinal hypoperfusion resulting in stress ulcers. Illustratively, Vaduganathan et al. reported that Global Use of Strategies to Open Occluded Coronary Arteries (GUSTO) moderate or mild bleeding occurred in $29 \%$ of cangrelor-treated patients in clinical shock within $48 \mathrm{~h}$ [12]. The bleeding rate in clinical shock patients was approximately twice as high as in hemodynamically stable patients [12]. Strategies to minimizing bleeding events in this vulnerable population might be increasing use of radial access and avoiding concurrent administration of glycoprotein IIb/IIIb inhibitors [12]. In line with other observational studies, cangrelor was only rarely combined with glycoprotein $\mathrm{IIb} / \mathrm{III}$ inhibitors in our cohort $[11,12]$. Post hoc analyses in CHAMPION already showed that cangrelor's efficacy in patients undergoing PCI was maintained irrespective of glycoprotein IIb/IIIa inhibitor use and that cangrelor alone was associated with a similar ischemic risk and lower risk-adjusted bleeding risk compared with clopidogrel combined with glycoprotein IIb/IIIa inhibitors [23,24].

\subsection{Timing and Choice of Oral P2 $Y_{12}$-Inhibititors}

The efficacy and safety of cangrelor was originally compared with clopidogrel and not with the more potent $\mathrm{P}_{2} \mathrm{Y}_{12}$-inhibitors ticagrelor or prasugrel [7], which are the standardof-care according to current guidelines $[1,25]$. In two out of the three CHAMPION trials, pretreatment (before PCI) with clopidogrel was not required, although this is common practice in the Netherlands [5,6]. In the current study, one quarter of patients received a $\mathrm{P}_{2} \mathrm{Y}_{12}$-inhibitor pre-PCI, although cangrelor is officially only indicated in patients who have not received an oral $\mathrm{P}_{2} \mathrm{Y}_{12}$-inhibitor prior to PCI. Importantly, the Platelet Inhibition With Cangrelor and Crushed Ticagrelor in STEMI Patients Undergoing Primary Percutaneous Coronary Intervention (CANTIC) study showed that (crushed) ticagrelor could be concomitantly administered with cangrelor without any apparent drug-drug interaction [26]. Other studies have shown that platelet inhibition during the transition from cangrelor to ticagrelor is maintained $[27,28]$. Conversely, the transition from cangrelor to clopidogrel and prasugrel is hampered by the competitive pharmacodynamics effects of these agents [29-31]. Therefore, oral loading with clopidogrel or prasugrel should take place only after the end of cangrelor infusion, possibly leaving a small, but critical, time window for inappropriate platelet aggregation [28].

\subsection{Future Directions}

Balancing ischemic and bleeding risk in high-risk patients, such as patients in cardiogenic shock or after cardiac arrest, remains a major challenge in clinical practice. At present, 
these patients are most often treated with cangrelor followed by ticagrelor (administered orally or through a nasogastric tube). Future studies should further investigate the added value of cangrelor in these high-risk patients, preferably in randomized controlled trials. Currently, the Dual Antiplatelet Therapy For Shock Patients With Acute Myocardial Infarction (DAPT-SHOCK-AMI) trial (ClinicalTrials.gov Identifier: NCT03551964) is comparing cangrelor and ticagrelor (administered orally or through a nasogastric tube) in 304 patients with acute myocardial infarction complicated by cardiogenic shock and treated with primary PCI. Hopefully, this trial will provide more insight into the net clinical effect (the combination of major adverse cardiac events and bleeding events) of cangrelor in high-risk patients. Similarly, the Cangrelor in Comatose Survivors of OHCA Undergoing Primary PCI (Cangrelor OHCA) trail (ClinicalTrials.gov Identifier: NCT04005729) is investigating if a $4 \mathrm{~h}$ continuous infusion of cangrelor at the start of primary PCI immediately and effectively suppresses platelet activity in comatose survivors of cardiac arrest. Results of these and other trials are eagerly awaited.

\subsection{Limitatioins}

Our study has several limitations. Our study is descriptive in nature and there is no formal control group for the cangrelor-treated patients. Data were collected retrospectively, leaving open the possibility of information bias, especially in patients who died soon after being admitted. Furthermore, we only studied the rate of definite stent thrombosis, which requires angiographic or pathological confirmation and might therefore underestimate the true stent thrombosis rate. Moreover, the sample size was limited, therefore the study was not powered to investigate predictors of 30-day mortality and possible subgroup differences (e.g., sex differences). Finally, the study was conducted in tertiary PCI centers and results may therefore not be generalizable to all PCI centers.

\section{Conclusions}

In routine practice, cangrelor was used almost exclusively in STEMI patients undergoing PCI. Even though cangrelor was used in high-risk patients, often requiring cardiopulmonary resuscitation or mechanical ventilation, its use was associated with a low rate of stent thrombosis.

Author Contributions: Conceptualization, N.M.R.v.d.S., H.Y.C., W.J.K. and J.P.S.H.; data curation, N.J.W.V., Y.A., M.A.M.B., B.E.P.M.C., R.D., P.K., J.S.L., A.N., M.M.V. and J.P.S.H.; methodology, N.M.R.v.d.S., H.Y.C., W.J.K. and J.P.S.H.; formal analysis, N.M.R.v.d.S., H.Y.C., W.J.K. and J.P.S.H.; supervision, J.P.S.H.; project ad-ministration, N.M.R.v.d.S.; writing-original draft preparation, N.M.R.v.d.S., H.Y.C., W.J.K. and J.P.S.H.; writing-review and editing, N.J.W.V., Y.A., M.A.M.B., B.E.P.M.C. and R.D. All authors have read and agreed to the published version of the manuscript.

Funding: This research received no external funding.

Institutional Review Board Statement: The study was conducted according to the guidelines of the Declaration of Helsinki, and approved by the Institutional Review Boards of the Academic Medical Center (W20_323 \#20.358, 9 July 2020) and VU University Medical Center (2020.495, 2 September 2020).

Informed Consent Statement: Patient consent was waived due to the fact that (i) some patients were deceased or untraceable and (ii) there was a substantial risk of response bias. In accordance with the standard operating procedure for the reuse of care data for the purpose of research, patients were given a four-week period to object to the reuse of their clinical care data.

Data Availability Statement: Data are available upon reasonable request.

Conflicts of Interest: J.P.S.H. has received research grants from Abbott Vascular, AstraZeneca, B. Braun, Getinge, Grupo Ferrer Internacional and Infraredx. M.A.M.B. has received a research grant from Actelion (Johnson \& Johnson). W.J.K. has received a research grant from AstraZeneca. N.M.R.v.d.S., H.Y.C., N.J.W.V., Y.A., B.E.P.M.C., R.D., P.K., J.S.L., A.N. and M.M.V. do not have any conflict of interest to declare. 


\section{References}

1. Collet, J.-P.; Thiele, H.; Barbato, E.; Barthélémy, O.; Bauersachs, J.; Bhatt, D.L.; Dendale, P.; Dorobantu, M.; Edvardsen, T.; Folliguet, T.; et al. 2020 ESC Guidelines for the management of acute coronary syndromes in patients presenting without persistent ST-segment elevation: The Task Force for the management of acute coronary syndromes in patients presenting without persistent ST-segment elevation of the European Society of Cardiology (ESC). Eur. Heart J. 2021, 42, 1289-1367. [CrossRef]

2. Ibanez, B.; James, S.; Agewall, S.; Antunes, M.J.; Bucciarelli-Ducci, C.; Bueno, H.; Caforio, A.L.P.; Crea, F.; Goudevenos, J.A.; Halvorsen, S.; et al. 2017 ESC Guidelines for the management of acute myocardial infarction in patients presenting with STsegment elevation: The Task Force for the management of acute myocardial infarction in patients presenting with ST-segment elevation of the European Society of Cardiology (ESC). Eur. Hear. J. 2018, 39, 119-177. [CrossRef]

3. Akers, W.S.; Oh, J.J.; Oestreich, J.H.; Ferraris, S.; Wethington, M.; Steinhubl, S.R. Pharmacokinetics and Pharmacodynamics of a Bolus and Infusion of Cangrelor: A Direct, Parenteral P2Y12 Receptor Antagonist. J. Clin. Pharmacol. 2010, 50, 27-35. [CrossRef]

4. Harrington, R.A.; Stone, G.W.; McNulty, S.; White, H.D.; Lincoff, A.M.; Gibson, C.M.; Pollack, C.V.; Montalescot, G.; Mahaffey, K.W.; Kleiman, N.S.; et al. Platelet Inhibition with Cangrelor in Patients Undergoing PCI. N. Engl. J. Med. 2009, 361, $2318-2329$. [CrossRef] [PubMed]

5. $\quad$ Bhatt, D.L.; Lincoff, A.M.; Gibson, C.M.; Stone, G.W.; McNulty, S.; Montalescot, G.; Kleiman, N.S.; Goodman, S.G.; White, H.D.; Mahaffey, K.W.; et al. Intravenous Platelet Blockade with Cangrelor during PCI. N. Engl. J. Med. 2009, 361, 2330-2341. [CrossRef]

6. Bhatt, D.L.; Stone, G.W.; Mahaffey, K.W.; Gibson, C.M.; Steg, P.G.; Hamm, C.W.; Price, M.J.; Leonardi, S.; Gallup, D.; Bramucci, E.; et al. Effect of Platelet Inhibition with Cangrelor during PCI on Ischemic Events. N. Engl. J. Med. 2013, 368, 1303-1313. [CrossRef]

7. Steg, P.G.; Bhatt, D.L.; Hamm, C.W.; Stone, G.W.; Gibson, C.M.; Mahaffey, K.W.; Leonardi, S.; Liu, T.; Skerjanec, S.; Day, J.; et al. Effect of cangrelor on periprocedural outcomes in percutaneous coronary interventions: A pooled analysis of patient-level data. Lancet 2013, 382, 1981-1992. [CrossRef]

8. Thygesen, K.; Alpert, J.S.; Jaffe, A.S.; Chaitman, B.R.; Bax, J.J.; Morrow, D.A.; White, H.D. Fourth Universal Definition of Myocardial Infarction (2018). J. Am. Coll. Cardiol. 2018, 72, 2231-2264. [CrossRef] [PubMed]

9. Cutlip, D.E.; Windecker, S.; Mehran, R.; Boam, A.; Cohen, D.J.; Van Es, G.-A.; Steg, P.G.; Morel, M.-A.; Mauri, L.; Vranckx, P.; et al. Clinical End Points in Coronary Stent Trials. Circulation 2007, 115, 2344-2351. [CrossRef] [PubMed]

10. Mehran, R.; Rao, S.V.; Bhatt, D.L.; Gibson, C.M.; Caixeta, A.; Eikelboom, J.; Kaul, S.; Wiviott, S.D.; Menon, V.; Nikolsky, E.; et al. Standardized Bleeding Definitions for Cardiovascular Clinical Trials: A consensus report from the bleeding academic research consortium. Circulation 2011, 123, 2736-2747. [CrossRef]

11. Grimfjärd, P.; Lagerqvist, B.; Erlinge, D.; Varenhorst, C.; James, S. Clinical use of cangrelor: Nationwide experience from the Swedish Coronary Angiography and Angioplasty Registry (SCAAR). Eur. Hear. J. Cardiovasc. Pharmacother. 2019, 5, 151-157. [CrossRef] [PubMed]

12. Vaduganathan, M.; Qamar, A.; Badreldin, H.A.; Faxon, D.P.; Bhatt, D.L. Cangrelor Use in Cardiogenic Shock: A Single-Center Real-World Experience. JACC: Cardiovasc. Interv. 2017, 10, 1712-1714. [CrossRef]

13. Iqbal, J.; Sumaya, W.; Tatman, V.; Parviz, Y.; Morton, A.C.; Grech, E.D.; Campbell, S.; Storey, R.F.; Gunn, J. Incidence and predictors of stent thrombosis: A single-centre study of 5,833 consecutive patients undergoing coronary artery stenting. EuroIntervention 2013, 9, 62-69. [CrossRef] [PubMed]

14. Parodi, G.; Valenti, R.; Bellandi, B.; Migliorini, A.; Marcucci, R.; Comito, V.; Carrabba, N.; Santini, A.; Gensini, G.F.; Abbate, R.; et al. Comparison of Prasugrel and Ticagrelor Loading Doses in ST-Segment Elevation Myocardial Infarction Patients. J. Am. Coll. Cardiol. 2013, 61, 1601-1606. [CrossRef] [PubMed]

15. Alexopoulos, D.; Xanthopoulou, I.; Gkizas, V.; Kassimis, G.; Theodoropoulos, K.C.; Makris, G.; Koutsogiannis, N.; Damelou, A.; Tsigkas, G.; Davlouros, P.; et al. Randomized Assessment of Ticagrelor Versus Prasugrel Antiplatelet Effects in Patients with ST-Segment-Elevation Myocardial Infarction. Circ. Cardiovasc. Interv. 2012, 5, 797-804. [CrossRef] [PubMed]

16. Součková, L.; Opatřilová, R.; Suk, P.; Čundrle, I.; Pavlík, M.; Zvoníček, V.; Hlinomaz, O.; Šrámek, V. Impaired bioavailability and antiplatelet effect of high-dose clopidogrel in patients after cardiopulmonary resuscitation (CPR). Eur. J. Clin. Pharmacol. 2012, 69, 309-317. [CrossRef] [PubMed]

17. Ratcovich, H.; Sadjadieh, G.; Andersson, H.; Frydland, M.; Wiberg, S.; Dridi, N.; Kjaergaard, J.; Holmvang, L. The effect of TIcagrelor administered through a nasogastric tube to COMAtose patients undergoing acute percutaneous coronary intervention: The TICOMA study. EuroIntervention 2017, 12, 1782-1788. [CrossRef]

18. Weeks, P.A.; Sieg, A.; Paruthi, C.; Rajapreyar, I. Antiplatelet Therapy Considerations in Ischemic Cardiogenic Shock. J. Cardiovasc. Pharmacol. Ther. 2015, 20, 370-377. [CrossRef]

19. Steblovnik, K.; Blinc, A.; Mijovski, M.B.; Kranjec, I.; Melkič, E.; Noc, M. Platelet reactivity in comatose survivors of cardiac arrest undergoing percutaneous coronary intervention and hypothermia. EuroIntervention 2015, 10, 1418-1424. [CrossRef]

20. Ibrahim, K.; Christoph, M.; Schmeinck, S.; Schmieder, K.; Steiding, K.; Schoener, L.; Pfluecke, C.; Quick, S.; Mues, C.; Jellinghaus, S.; et al. High rates of prasugrel and ticagrelor non-responder in patients treated with therapeutic hypothermia after cardiac arrest. Resuscitation 2014, 85, 649-656. [CrossRef]

21. Parodi, G.; Bellandi, B.; Xanthopoulou, I.; Capranzano, P.; Capodanno, D.; Valenti, R.; Stavrou, K.; Migliorini, A.; Antoniucci, D.; Tamburino, C.; et al. Morphine Is Associated with a Delayed Activity of Oral Antiplatelet Agents in Patients With ST-Elevation Acute Myocardial Infarction Undergoing Primary Percutaneous Coronary Intervention. Circ. Cardiovasc. Interv. 2015, 8. [CrossRef] [PubMed] 
22. Kubica, J.; Adamski, P.; Ostrowska, M.; Sikora, J.; Kubica, J.M.; Sroka, W.D.; Stankowska, K.; Buszko, K.; Navarese, E.; Jilma, B.; et al. Morphine delays and attenuates ticagrelor exposure and action in patients with myocardial infarction: The randomized, double-blind, placebo-controlled IMPRESSION trial. Eur. Hear. J. 2016, 37, 245-252. [CrossRef] [PubMed]

23. Vaduganathan, M.; Harrington, R.A.; Stone, G.W.; Deliargyris, E.N.; Steg, P.G.; Gibson, C.M.; Hamm, C.W.; Price, M.J.; Menozzi, A.; Prats, J.; et al. Cangrelor With and Without Glycoprotein IIb/IIIa Inhibitors in Patients Undergoing Percutaneous Coronary Intervention. J. Am. Coll. Cardiol. 2017, 69, 176-185. [CrossRef] [PubMed]

24. Vaduganathan, M.; Harrington, R.A.; Stone, G.W.; Deliargyris, E.N.; Steg, P.G.; Gibson, C.M.; Hamm, C.W.; Price, M.J.; Menozzi, A.; Prats, J.; et al. Evaluation of Ischemic and Bleeding Risks Associated with 2 Parenteral Antiplatelet Strategies Comparing Cangrelor with Glycoprotein IIb/IIIa Inhibitors. JAMA Cardiol. 2017, 2, 127-135. [CrossRef]

25. Valgimigli, M.; Bueno, H.; Byrne, R.; Collet, J.-P.; Costa, F.; Jeppsson, A.; Jüni, P.; Kastrati, A.; Kolh, P.; Mauri, L.; et al. 2017 ESC focused update on dual antiplatelet therapy in coronary artery disease developed in collaboration with EACTS. Eur. J. Cardio Thora. Surg. 2018, 53, 34-78. [CrossRef] [PubMed]

26. Franchi, F.; Rollini, F.; Rivas, A.; Wali, M.; Briceno, M.; Agarwal, M.; Shaikh, Z.; Nawaz, A.; Silva, G.; Been, L.; et al. Platelet Inhibition With Cangrelor and Crushed Ticagrelor in Patients With ST-Segment-Elevation Myocardial Infarction Undergoing Primary Percutaneous Coronary Intervention. Circulation 2019, 139, 1661-1670. [CrossRef] [PubMed]

27. Mohammad, M.A.; Andell, P.; Koul, S.; James, S.; Scherstén, F.; Götberg, M.; Erlinge, D. Cangrelor in combination with ticagrelor provides consistent and potent P2Y12-inhibition during and after primary percutaneous coronary intervention in real-world patients with ST-segment-elevation myocardial infarction. Platelets 2017, 28, 414-416. [CrossRef]

28. Hochholzer, W.; Kleiner, P.; Younas, I.; Valina, C.M.; Löffelhardt, N.; Amann, M.; Bömicke, T.; Ferenc, M.; Hauschke, D.; Trenk, D.; et al. Randomized Comparison of Oral P2Y12-Receptor Inhibitor Loading Strategies for Transitioning from Cangrelor: The ExcelsiorLOAD2 Trial. JACC Cardiovasc. Interv. 2017, 10, 121-129. [CrossRef] [PubMed]

29. Schneider, D.J.; Agarwal, Z.; Seecheran, N.; Gogo, P. Pharmacodynamic Effects When Clopidogrel Is Given before Cangrelor Discontinuation. J. Interv. Cardiol. 2015, 28, 415-419. [CrossRef]

30. Judge, H.M.; Buckland, R.; Jakubowski, J.A.; Storey, R. Cangrelor inhibits the binding of the active metabolites of clopidogrel and prasugrel to P2Y12receptorsin vitro. Platelets 2015, 27, 191-195. [CrossRef]

31. Dovlatova, N.L.; Jakubowski, J.A.; Sugidachi, A.; Heptinstall, S. The reversible P2Y12antagonist cangrelor influences the ability of the active metabolites of clopidogrel and prasugrel to produce irreversible inhibition of platelet function. J. Thromb. Haemost. 2008, 6, 1153-1159. [CrossRef] [PubMed] 